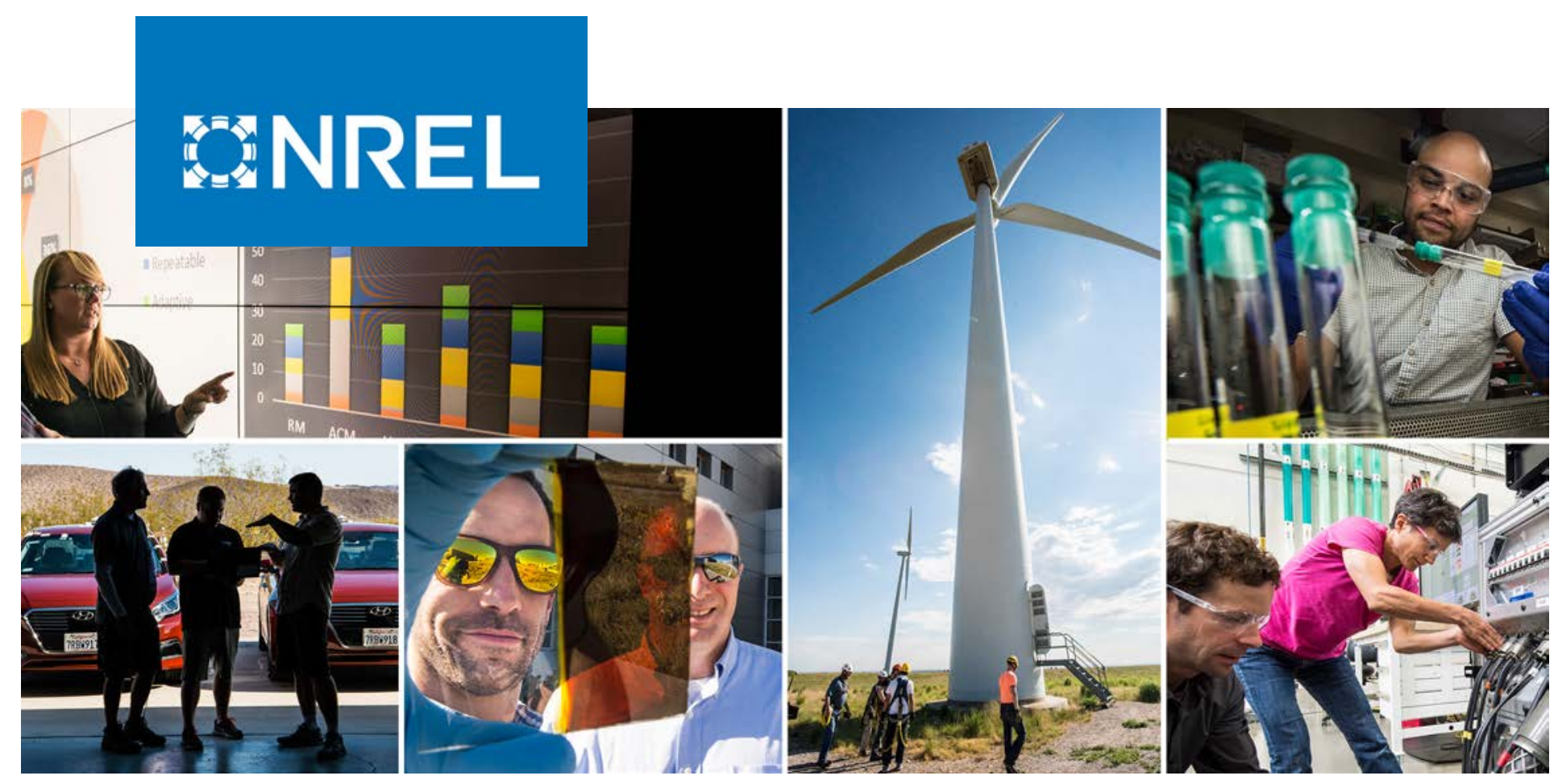

\title{
Life-Cycle Cost and Optimization of PV Systems Based on Power Duration Curve with Variable Performance Ratio and Availability
}

\author{
Andy Walker, ${ }^{1}$ Jal Desai, ${ }^{1}$ and Ammar Qusaibaty ${ }^{2}$ \\ ${ }^{1}$ National Renewable Energy Laboratory \\ 2 U.S. Department of Energy (contractor)
}

NREL is a national laboratory of the U.S. Department of Energy Office of Energy Efficiency \& Renewable Energy

Operated by the Alliance for Sustainable Energy, LLC

This report is available at no cost from the National Renewable Energy Laboratory (NREL) at www.nrel.gov/publications.

\section{Technical Report}

NREL/TP-5C00-73850

February 2020 


\title{
GHREL
}

\section{Life-Cycle Cost and Optimization of PV Systems Based on Power Duration Curve with Variable Performance Ratio and Availability}

\author{
Andy Walker, ${ }^{1}$ Jal Desai, ${ }^{1}$ and Ammar Qusaibaty ${ }^{2}$ \\ ${ }^{1}$ National Renewable Energy Laboratory \\ 2 U.S. Department of Energy (contractor)
}

\section{Suggested Citation}

Walker, Andy, Jal Desai, and Ammar Qusaibaty. 2020. Life-Cycle Cost and Optimization of PV Systems Based on Power Duration Curve with Variable Performance Ratio and Availability. Golden, CO: National Renewable Energy Laboratory. NREL/TP-5C00-73850. https://www.nrel.gov/docs/fy20osti/73850.pdf.

NREL is a national laboratory of the U.S. Department of Energy Office of Energy Efficiency \& Renewable Energy Operated by the Alliance for Sustainable Energy, LLC

This report is available at no cost from the National Renewable Energy Laboratory (NREL) at www.nrel.gov/publications.

Contract No. DE-AC36-08GO28308
Technical Report NREL/TP-5C00-73850

February 2020

National Renewable Energy Laboratory 15013 Denver West Parkway Golden, CO 80401 303-275-3000 • www.nrel.gov 


\section{NOTICE}

This work was authored in part by the National Renewable Energy Laboratory, operated by Alliance for Sustainable Energy, LLC, for the U.S. Department of Energy (DOE) under Contract No. DE-AC36-08GO28308. Funding provided by the U.S. Department of Energy Office of Energy Efficiency and Renewable Energy Solar Energy Technologies Office under agreement \#32174. The views expressed herein do not necessarily represent the views of the DOE or the U.S. Government.

This report is available at no cost from the National Renewable Energy Laboratory (NREL) at www.nrel.gov/publications.

U.S. Department of Energy (DOE) reports produced after 1991 and a growing number of pre-1991 documents are available free via www.OSTI.gov.

Cover Photos by Dennis Schroeder: (clockwise, left to right) NREL 51934, NREL 45897, NREL 42160, NREL 45891, NREL 48097, NREL 46526.

NREL prints on paper that contains recycled content. 


\section{Acknowledgments}

Funding provided to the National Renewable Energy Laboratory (NREL) by the U.S. Department of Energy (DOE) Solar Energy Technologies Office (SETO) under Agreement 32315 to perform this work is gratefully acknowledged. Assistance of Linda Crow and Mary Lukkonen of NREL in preparing the manuscript is gratefully acknowledged.

This work was authored in part by NREL, operated by Alliance for Sustainable Energy, LLC, for the U.S. Department of Energy (DOE) under Contract No. DE-AC36-08GO28308. Funding provided by the U.S. Department of Energy Office of Energy Efficiency and Renewable Energy Solar Energy Technologies Office. The views expressed in the report do not necessarily represent the views of DOE or the U.S. Government. The U.S. Government retains and the publisher, by accepting the article for publication, acknowledges that the U.S. Government retains a nonexclusive, paid-up, irrevocable, worldwide license to publish or reproduce the published form of this work, or allow others to do so, for U.S. Government purposes. 


$\begin{array}{ll}\text { List of Acronyms and Symbols } \\ \delta & \text { temperature coefficient of power }\left(1 /{ }^{\circ} \mathrm{C}\right) \\ \eta & \text { efficiency } \\ \text { A } & \text { availability } \\ \text { AC } & \text { alternating current } \\ \text { C } & \text { cost }(\$) ; \text { present value. } \\ \text { c } & \text { per unit cost for the DC or AC components of the PV system }(\$ / \mathrm{kW}) \\ \text { C F } & \text { capacity factor } \\ \text { DC } & \text { direct current } \\ \text { degr } & \text { age degradation factor to represent the cumulative lost production over a } \\ & \text { multiyear analysis period } \\ \text { dLCC } & \text { differential of life cycle cost }(\$) \\ \text { dP } & \text { differential of rated power capacity }(\mathrm{kW}), \text { of inverter in this example } \\ \text { E } & \text { annual energy quantity }(\mathrm{kWh} / \text { year) } \\ \text { IEC } & \text { International Electrotechnical Commission } \\ \mathrm{kW} & \text { kilowatt } \\ \mathrm{kWh} & \text { kilowatt hour } \\ \text { LCC } & \text { life cycle cost } \\ \mathrm{n} & \text { a parameter in derivation of duration curve depending only on CF } \\ \text { O\&M } & \text { operation and maintenance } \\ \text { oSPARC } & \text { Open System Performance and Reliability Clearinghouse } \\ \text { P } & \text { power }(\mathrm{kW}) \\ \text { PR } & \text { performance ratio } \\ \text { PV } & \text { photovoltaic } \\ \text { PVPS } & \text { photovoltaic power systems } \\ \text { PWF } & \text { present worth factor } \\ \mathrm{r} & \text { price saved or paid by others for delivery of electric energy from the PV } \\ \text { SETO } & \text { system }(\$ / \mathrm{kWh}) \\ \mathrm{t} & \text { Solar Energy Technology Office } \\ \text { T } & \text { duration of time within analysis period T (hours) } \\ \text { TMY } & \text { total time duration of analysis period (hours) } \\ \text { DOE } & \text { typical meteorological year } \\ & \text { U.S. Department of Energy }\end{array}$




\section{List of Symbols with Subscripts}

$\eta_{\text {Inverter, BOS }}$

$\mathrm{C}_{\text {initial,fixed }}$

$\mathrm{c}_{\text {initial, DC }}$

$\mathrm{c}_{\text {initial, } \mathrm{AC}}$

Co\&M, fixed

Co\&M, DC

C O\&M, AC

$\mathrm{E}_{\text {actual }}$

$\mathrm{E}_{\text {clipped }}$

$\mathrm{E}$ expected

$\mathrm{E}$ production

I POA

I ref

P actual

$\mathrm{P}_{\text {expected }}$

$\mathrm{P}_{\text {inverter }}$

$\mathrm{P}_{\text {rated }}$

P

$r_{\text {electricity }}$

$T$ ambient efficiency of inverter and balance-of-system

initial cost of the PV system that is fixed and independent of size (\$)

per unit initial cost for the DC components of the system, such as PV array $(\$ / \mathrm{kW})$

per unit initial cost for the $\mathrm{AC}$ components of the system including inverter and transformer $(\$ / \mathrm{kW})$

annual operation and maintenance cost of the PV system that is fixed and independent of size (\$/year)

annual operation and maintenance cost for the DC components of the system, such as PV array $(\$ / \mathrm{kW} /$ year $)$

annual operation and maintenance cost for the $\mathrm{AC}$ components such as inverter and transformer $(\$ / \mathrm{kW} /$ year $)$

actual energy output of a PV system $(\mathrm{kWh})$

DC Energy (kWh) potentially generated by PV array but not converted

into $\mathrm{AC}$ due to inverter size

expected annual energy output of a PV system (kW) under specified

conditions and time period

annual energy production $(\mathrm{kWh})$ based on rated power and capacity factor

(before inverter clipping)

plane of array (POA) Irradiance $(\mathrm{W} / \mathrm{m} 2)$

insolation level corresponding to the associated rating standard

actual power output of a PV system $(\mathrm{kW})$

expected power output of a PV system $(\mathrm{kW})$ under specified conditions

rated capacity of inverter $(\mathrm{kW})$

rated $\mathrm{AC}$ power output of a $\mathrm{PV}$ system $(\mathrm{kW})$ considering maximum output and balance-of-system efficiency

rated DC power $(\mathrm{kW})$ under PVUSA Test Conditions

price saved or paid by others for delivery of electric energy from the PV system $(\$ / \mathrm{kWh})$

ambient temperature $\left({ }^{\circ} \mathrm{C}\right)$ 


\section{Executive Summary}

This report presents a new functional form for annual power duration curve for a photovoltaic power system; evaluates the accuracy of the duration curve equation in matching hourly solar resource data at cloudy, sunny, and average locations; derives scalar integrals of interest; and incorporates the functional dependence of imperfect performance ratio $(\mathrm{PR})(\mathrm{PR}<1)$ and availability $(\mathrm{A}<1)$. The dependence of $\mathrm{PR}<1$ and $\mathrm{A}<1$ on $\mathrm{PV}$ system life cycle cost (LCC) and on design decisions is explored. Here we differentiate between the effects of PR, which is defined as a reduction in the instantaneous efficiency of the system, and Availability, which quantifies time that the plant is in service. It is exposed how PR and availability influence LCC and design decisions in different ways. Practitioners already optimize LCC based on component costs; solar resources; utility policy (interconnect limits, curtailment, net-metering); utility rate-schedule; and incentives available from government agencies and utilities. This new method introduces effects of PR and Availability data and O\&M costs into the LCC optimization. The utility of the method is illustrated by an example of optimizing inverter sizing (DC/AC ratio), considering non-unity $(<1)$ PR and Availability. Results show a very strong dependence of optimal DC/AC ratio on PR, and a weaker but non-negligible dependence on Availability and indicate that non-unity values of these performance parameters should be considered even in the early feasibility study and design phases of a project. 


\section{Table of Contents}

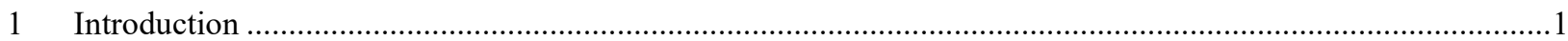

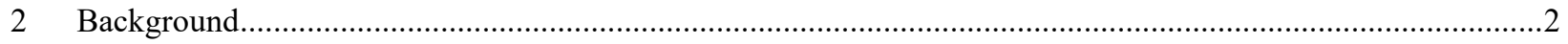

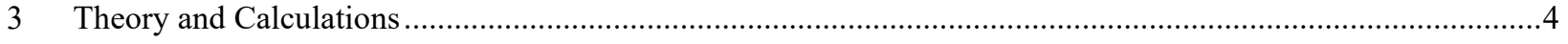

3.1 Power Duration Curve Based on Solar Resource ........................................................................

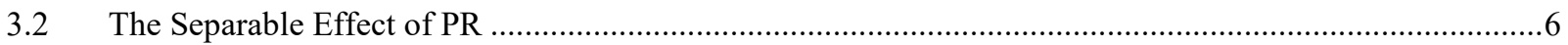

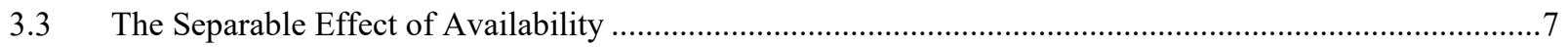

3.4 Estimated Annual Energy Production and Power Duration Curve Modified by PR $<1$ and A<1 ...............9

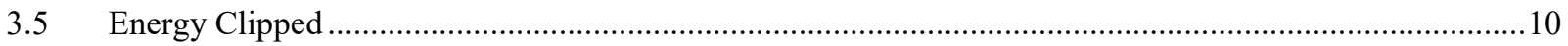

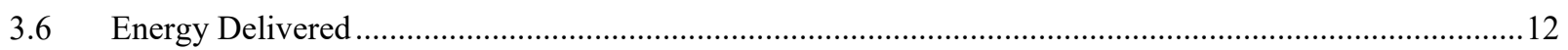

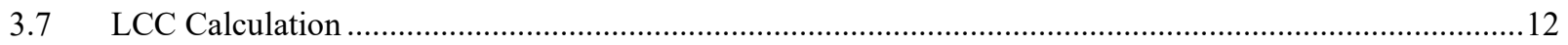

3.8 Example Application: Optimization of LCC Considering Effects of PR and Availability ......................13

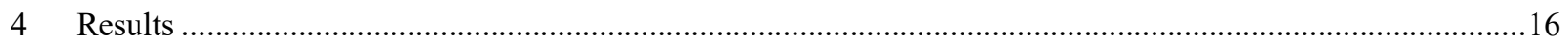

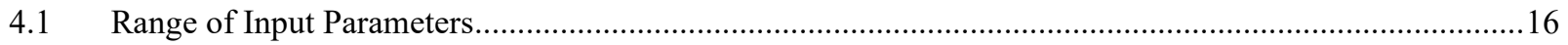

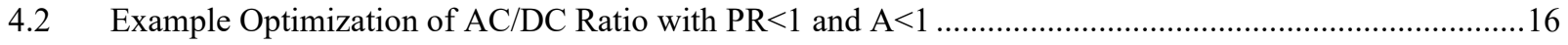

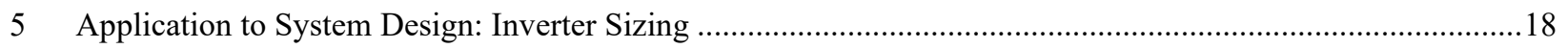

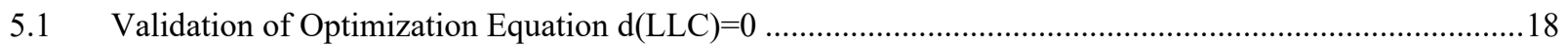

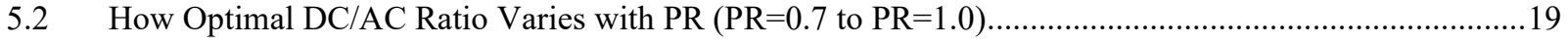

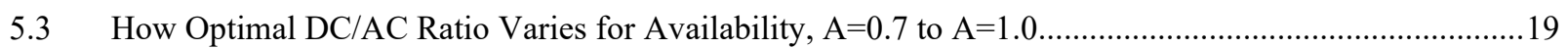

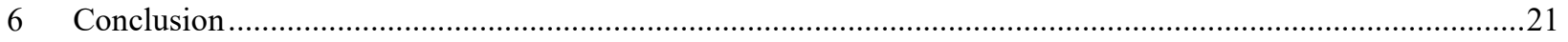

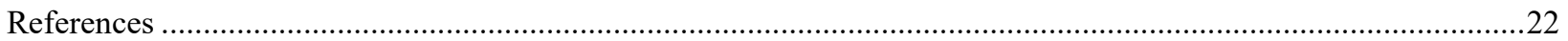




\section{List of Figures}

Figure 1. Duration curve of Equation 2 and hourly TMY data for Quillayute, Washington; Daggett, California; and Athens, Georgia [23]

Figure 2. The duration curve for PV power production is affected differently by a change in PR (a) than it is for availability (b), which has implications for amount of inverter clipping and optimal AC/DC ratio. [figure by the author]

Figure 3. LCC calculated from Equation 19, compared to the optimal DC/AC ratio calculated using Equation 23 [figure by the author]

\section{List of Tables}

Table 1. Minimum Values, Average Values and Standard Deviation, and Maximum Values of PR Based on Equation 4 for 2,200 PV Systems in California.

Table 2. Selected values of Input Parameters to use in an example of the LCC and Optimization Calculations (\$/kW

refers to $\mathrm{kW}$ of $\left.\mathrm{P}_{\text {rated }}\right)$........

Table 3. Example of Output Results for LCC and Optimization Calculations, including the effect of non-unity PR and Availability (using the input values from Table 2)

Table 4. Optimal AC/DC Ratio as a Function of Varying PR, with Other Values Held at the values listed in Table 3

Table 5. Optimal DC/AC Ratio as a Function of Varying Availability, with Other Values Held from Table 2. .......20 


\section{Introduction}

This report introduces imperfect performance ratio (PR) and availability in the optimization of photovoltaic (PV) system parameters based on life cycle cost (LCC). An optimization involves: objective function, variables, and constraints. In this derivation, the objective function is LCC. Any of the variables in the objective function may be the variables of the optimization, and here, as an example, we select DC/AC ratio as the design parameter to optimize - that is the rated capacity of the PV array in DC divided by the inverter capacity. This ratio has increased from 1.2 to 1.3 in recent years as the price of PV modules has declined [1] and constraints have emerged on $\mathrm{AC}$ utility interconnection capacity. The optimization may include constraints; for example, utility regulations might say the $\mathrm{DC} / \mathrm{AC}$ ratio must be at least $1.4(\mathrm{AC} / \mathrm{DC}<0.70)$ to allow more hosting capacity on the network. The method presented here for PV may be adapted for different technologies, such as wind power, and different objective functions, such as carbon savings. In the calculation of life cycle cost, all energy produced by the PV system is valued at the same $\$ / \mathrm{kWh}$ rate, so the result would not be accurate when the PV system is off-setting a utility rate dominated by demand or time-of-use charges. 


\section{Background}

Research into PV system performance ratio (PR) and operation and maintenance (O\&M) costs by researchers and industry collaborators has identified implications for operational parameters (as opposed to equipment parameters) in LCC analysis and PV system design. In 2016-2018, the U.S. Department of Energy (DOE) Solar Energy Technologies Office (SETO) supported an industry-led PV O\&M working group, consisting of 113 industry stakeholders, that resulted in publication of the Best Practices for Operation and Maintenance of Photovoltaic and Energy Storage Systems; 3rd Edition [2] performance and reliability data sets [3,4], and a pro forma PV O\&M cost model [5]. This working group was a key venue for working out definitions related to performance and availability.

Dierauf et al. [6] define PR and the calculation, and the justification behind using the weathercorrected PR for analysis. The Open System Performance and Reliability Clearinghouse (oSPARC) [3] logs performance data from connected systems and includes access to satellite solar resource data so that it can calculate and report PR. The oSPARC database now has nameplate and location data for a total of 5,500 systems in 43 states. 2,200 of these systems have enough detail in the plant description to calculate a PR, resulting in the benchmark PR $(\mathrm{PR}=91.7 \%)$ used in the example described in this report.

Regarding availability, International Electrotechnical Commission (IEC) Technical Specification 63019 [7] "Information Model of Photovoltaic Power Systems" has been published by IEC (see https://webstore.iec.ch/publication/27253). It categorizes various causes of unavailability and defines a common basis for exchange of information on photovoltaic power systems (PVPS) availability metrics among stakeholders. The current work draws on this body of work in the derivation of the method and to inform representative values used in the example analysis.

Kumar et al. [8] define the availability factor for the inverters and PV plant and evaluates the availability factor for a commissioned PV plant over 5 years, wherein the availability factor ranges from $92.44 \%-95.69 \%$, and describes the reasons behind the monitored results. As our benchmark value in this paper we assume $\mathrm{A}=0.95$.

With improving software and computing power, numerical methods prevail, and much literature describes time-series (hourly) simulation of PV system performance. Fewer papers describe analysis based on the power duration curve, which is a forfeiture of insight and information actionable by the practitioner. Analysis based on power duration curve exposes phenomena of interest to both PV system design, energy system integration, and performance evaluation. Damoulias [9] presents an analysis based on a linear power duration curve to compare different inverter models without having to perform multiple simulations. Faranda et al. [10] also optimize $\mathrm{DC} / \mathrm{AC}$ ratio using a cost analysis based on the duration curve. Faranda used a linear distribution for the monthly duration curve and a quadratic for the hourly duration curve. While a quadratic can match the shape of an empirical duration curve very closely, it is not based on a physical derivation and cannot represent varying PR and availability a priori. This report presents a new form of distribution function for the power duration curve derived especially for this application and based on the first law of thermodynamics and the definition of capacity factor [11]. This novel form of the distribution function is introduced here with the capability to accurately represent details of the underlying time-series data and variations in these operational performance parameters. 
Many authors describe different methods to optimally size the whole PV system or individual components to minimize LCC [12-16]. Our presentation is initiated with a description of what makes this report different - the mathematical formulation of the power duration curve. 


\section{Theory and Calculations}

A novel form of the power duration curve based on solar resource parameters is derived and modified to account for imperfect PR and availability. Scalar integrals for energy "clipped" by inverter size and power delivered to the offtaker are evaluated and used in a calculation of LCC. The derivative of the equation for LCC is set to zero to optimize system parameters, with size of inverter relative to PV array size optimized as an example.

\subsection{Power Duration Curve Based on Solar Resource}

We begin with a description of the new form of power duration curve. A PV system carries a rating of how much power it will deliver under standard conditions. The standard conditions modified to represent the most power that the PV could generate under ideal conditions (maximum sunlight and minimum temperature) is called here $\mathrm{P}$ maximum, DC. The rated power output of the PV system is defined here as this maximum output reduced by the efficiency of the

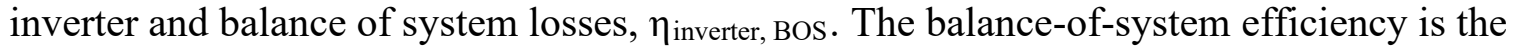
product of known inefficiencies, such as wiring losses and inverter inefficiency, which can be estimated and expected. Generally, this value of $\eta_{\text {inverter,BOS }}$ is considered a constant in the analysis, with varying effects such as soiling of the PV module surfaces being measured in the PR value, making PR of more interest to O\&M practitioners than $\eta_{\text {inverter, Bos. }}$

Equation 1

$$
P_{\text {rated }}=\mathrm{P}_{\text {maximum, } \mathrm{DC}} * \eta_{\text {inverter }, \text { Bos }}
$$

$\mathrm{P}_{\text {rated }}$ is the maximum value in our duration curve distribution function of power values. $\mathrm{P}(\mathrm{kW})$ is the DC power level of a PV array at any time, $t$ (hours). Data regarding the power output of a $\mathrm{PV}$ system is a function of the underlying solar resource at a location and may be displayed as a curve showing the value of $\mathrm{P}$ for each time interval in an analysis period, $\mathrm{T}$. Analysis period $\mathrm{T}$ is often 1 year, which in our treatment here repeats for the number of years in the system lifetime. An alternative would be to use a different duration curve for each year of the analysis period to account for changes in values over time. The duration curve for $\mathrm{P}(\mathrm{t})$ as a function of $\mathrm{t}$, depending on the solar resource (capacity factor at a location), is given by the distribution function of Equation 2.

Equation 2

$$
P=P_{\text {rated }}\left(1-(t / T)^{n}\right)
$$

Where $t / T$ is the fraction of the total time $T$, from a minimum of $t / T=0$ to a maximum of $t / T=1$. In general, $\mathrm{T}=8,760$ hours, where 8,760 is the number of hours of a single year, but for renewable energy generators that are powered by sunlight (photovoltaics, solar ventilation air preheating), only the 4,380 daytime hours in a year are included and $\mathrm{T}=4,380$. In Equation 2 there is only one time per year $(\mathrm{t} / \mathrm{T}=0)$ when $\mathrm{P}$ is equal to $\mathrm{P}_{\text {rated, }}$ but the data shown in Figure 1 appears to confirm that detail. The exponent $\mathrm{n}$ in equation 2 depends on the solar resource in a location. Invoking conservation of energy (first law of thermodynamics) requires that $n=\mathrm{CF} /(1$ $\mathrm{CF}$ ), where $\mathrm{CF}$ is the capacity factor for a given location. 
The capacity factor is defined as total energy $(\mathrm{kWh})$ divided by rated capacity $(\mathrm{kW})$ and time duration (hours). CF could be defined over any time period (hour, day, month) but is defined here as one year to accommodate seasonal variation in the solar resource in a single calculation. The capacity factor is derived from solar (or wind if that is the topic) resource data at a location, adjusted for and taken as a value read from resource databases, many listed on the Photovoltaic Software website [17] and specific to array orientation (tilt and azimuth angles or tracking configuration). $\mathrm{CF}$ values reported in the resource literature and databases are the fraction of solar energy incident on a surface divided by the energy that would be incident if the surface was exposed to full sun (for example, $1000 \mathrm{~W} / \mathrm{m}^{2}$ ) for the whole time period. On the other hand, $\mathrm{CF}$ values in conversion technology literature often include the effects of the solar resource but also balance-of-system efficiency, maintenance problems, and downtime. For this analysis, we adopt the definition that CF represents only the solar resource and not balance-of-system efficiency or maintenance problems and down-time, which we account for separately here.

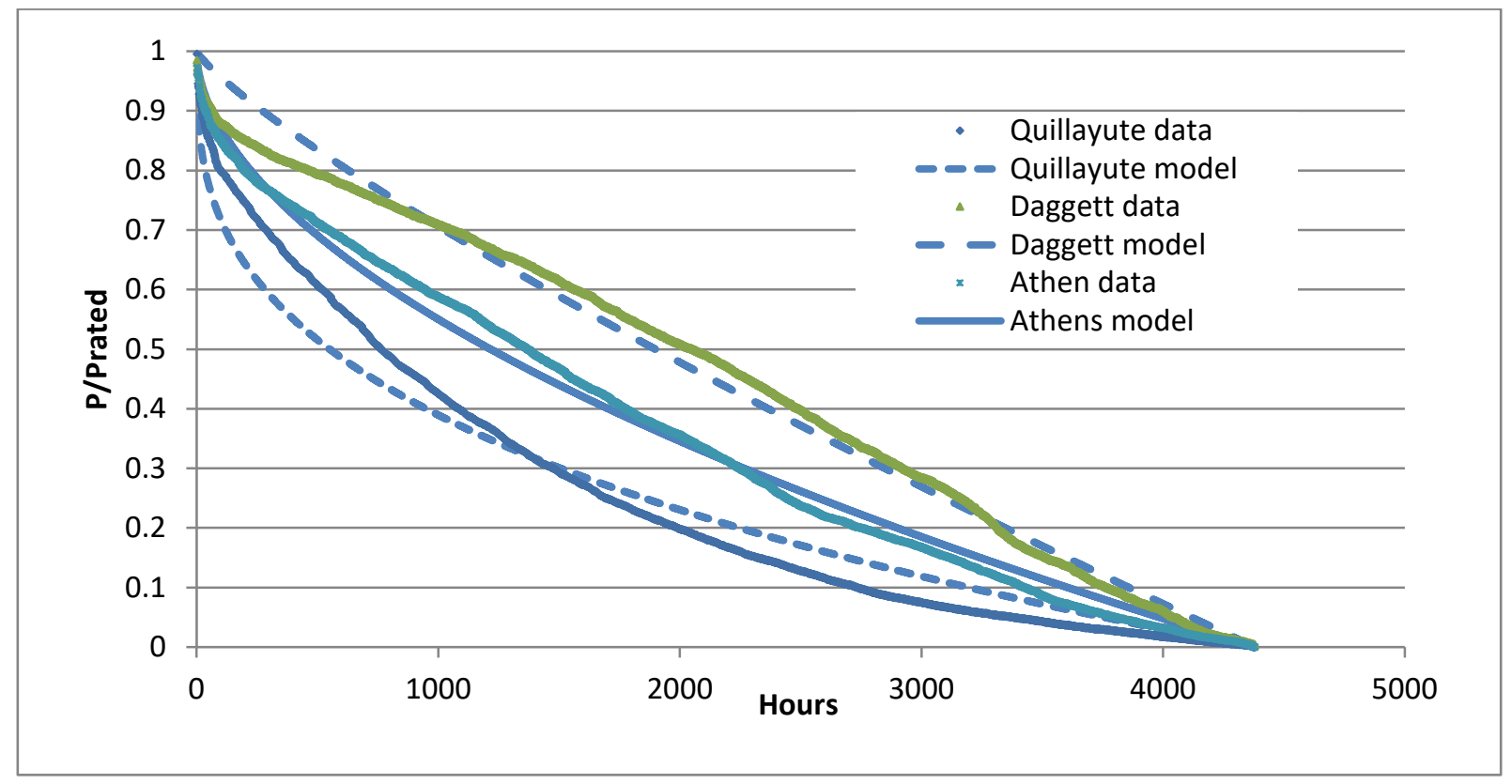

Figure 1. Duration curve of Equation 2 and hourly TMY data for Quillayute, Washington; Daggett, California; and Athens, Georgia [23]

This distribution function tends to overestimate high radiation levels and underestimate low radiation levels for a cloudy climate. Conversely, for a sunny climate, it tends to underestimate high radiation levels and overestimate low ones due to the dependence on CF in Equation 2. But, for locations that are not particularly sunny or particularly cloudy, the agreement is very good between the distribution model and the underlying data (hourly insolation data from https://nsrdb.nrel.gov/nsrdb-viewer [17]). For example, one of the cloudiest climates is in Quillayute, Washington, with a $\mathrm{CF}=0.25$, and the square of the Pearson product moment correlation coefficient $\left(\mathrm{R}^{2}\right.$ error) between the model and the underlying data is 0.9883; Daggett, California, is one of the sunniest climates, with $\mathrm{CF}=0.45$ and an $\mathrm{R}^{2}$ of 0.9898 . Athens, Georgia, is very typical with $\mathrm{CF}=0.35$ and $\mathrm{R}^{2}$ of 0.9946 . Thus, while there is more error in very sunny or very cloudy locations, the distribution model is sufficiently accurate $\left(\mathrm{R}^{2}>0.988\right)$ in all locations. The duration curve of Equation 2 for typical Meteorological Year (TMY) data for these three locations [17], along with the actual hourly data, is shown in Figure 1. Since the parameters of 
Equation 2 for the distribution are determined by conservation of energy (same amount of energy over the year), the area under the curve $(\mathrm{kWh} /$ year) is the same value as the model distribution as for the underlying time-series data (e.g., hourly).

\subsection{The Separable Effect of PR}

PR is often thought of as actual energy delivery divided by expected (modeled) energy delivery (this differs from CF in that the denominator is not full rated capacity output for the year, rather a calculation of expected output). The previous, conventional, way PR is calculated is measured delivery over a time period (day, month, year) in the numerator; however, the measured delivery over a year would be affected by both inefficiency in the system, such as might be caused by soiling of PV modules, and downtime as might be caused by inverter failure. Since we may define the PR over any time period, we must maintain the same definition in the limit as a time period becomes small.

Equation 3

$$
\lim _{T \rightarrow 0}\left(\frac{\Delta E_{\text {actual }}}{\Delta E_{\text {expected }}}\right)=\frac{P_{\text {actual }}}{P_{\text {expected }}}=P R
$$

The definition of PR simplifies to instantaneous (or nearly instantaneous, such as hourly) actual power divided by expected power. In our treatment here, the effect of system downtime is removed from the definition of PR. There are several definitions of PR, depending on rating conditions and applied corrections to the expected power delivery. A useful form is $\mathrm{P}_{\text {actual }}$, the measured power delivered by the inverter $(\mathrm{kW})$, divided by a calculation of how much power the system should have generated based on environmental conditions, age degradation, and $\eta_{\mathrm{BO}}$, by the following equation:

Equation 4

$$
P R=\frac{P_{\text {actual }}}{P_{P T C}\left(\frac{I_{P O A}}{I_{\text {ref }}}\right)\left\{\eta_{\text {BOS }} * \text { degr } *\left(1-\delta\left(T_{\text {ambient }}-20^{\circ} \mathrm{C}\right)\right)\right\}}
$$

Where the PV USA Test Condition (PTC) rating is the reference condition [18] and P PTC is adjusted by: $\delta=$ temperature coefficient of power $\left(1 /{ }^{\circ} \mathrm{C}\right)$, which is usually on the order of 0.004 $1 /{ }^{\circ} \mathrm{C}$ for silicon PV modules and may be less for other technologies; $\eta_{\mathrm{BOS}}=$ balance-of-system efficiency; typically $80 \%$ to $90 \%$ but stipulated based on published inverter efficiency and other system details such as wiring losses; degr = an age degradation factor that is 1.0 initially but degrades at a specified rate per year to represent the cumulative lost production over a multiyear analysis [19]; I POA = Plane of Array (POA) Irradiance, the sum of direct, diffuse, and groundreflected irradiance measured incident upon an inclined surface parallel to the plane of the modules in the PV array (units of $\mathrm{W} / \mathrm{m} 2$ ); $\mathrm{I}$ ref is the insolation level corresponding to the rating standard; and $\mathrm{T}_{\text {ambient }}=$ ambient temperature $\left({ }^{\circ} \mathrm{C}\right)$. 
Table 1. Minimum Values, Average Values and Standard Deviation, and Maximum Values of PR Based on Equation 4 for 2,200 PV Systems in California

\begin{tabular}{|l|c|}
\hline & PR \\
\hline Average & $91.7 \%$ \\
\hline Standard Deviation of Ave. & $16.5 \%$ \\
\hline Median & $91.3 \%$ \\
\hline
\end{tabular}

Source: SSPARC, 2018

Adjusting for all known corrections (insolation, temperature, balance-of-system efficiency, and age) the value of PR should ideally be 1.0. A value greater than 1.0 results when the expected energy production is underestimated. For example, the maximum $\mathrm{PR}=1.58$ in the example data set of Table 1 results from the user of the oSPARC database entering a very low balance-ofsystem efficiency, with the explanation that the system was expected to have a $40 \%$ shading loss. A low estimate, such as the minimum $P R=0.186$, could result if the estimate of expected energy production was too high by mistake, or if the actual performance of the system is low, which would be actionable information for the O\&M practitioner. We note that the estimate of expected production is just as important to the interpretation of PR as the measurement of production is.

\subsection{The Separable Effect of Availability}

An available state is when a PV system can provide service, regardless of whether it is actually in service and regardless of the efficiency and the power level that can be provided. Availability, A, is conventionally defined as the amount of time that a system can produce electricity, divided by the total amount of time in the specified period. Values of availability average $95.7 \%$ for 202 PV systems in Taiwan and $94.6 \%$ to $95.9 \%$ for 295 systems in Germany, Italy, Japan, and Switzerland [20]. Here we cite $95.6 \%$ as a benchmark value.

$\mathrm{A}$ is the number operational hours divided by the expected number of operational hours. PV systems do not generate at night, so the expected number of operational hours is $8,760 / 2=4,380$ hours per year. If a system is unavailable and not able to deliver power, the number of actual operational hours is reduced. Non-random events such as planned maintenance may reduce the expected operational hours, or more likely for well-maintained plants, such planned outages would be scheduled at night. The draft standard IEC 63019 "Photovoltaic Power Systems (PVPS) - Information Model For Availability" [7] provides a template to sort all the time periods of a year into information categories: a plant might be operation or non-operational; if it is operational it might be in service with full or partial capability, or it might be out of service due to out of electrical specification (grid is down) or requested shutdown. If a plant is nonoperational it might be due to scheduled maintenance shut down. Keeping track of the hours that a plant spends in each information category will be important for performance contracting and warranty guarantees regarding availability. Unplanned outages due to equipment failure could occur at any time, and here we assume that outage hours are distributed evenly across all the different power levels (for PV all the different times of day and days of year) that generation occurs, so that a value of $A<1$ reduces the total number of hours, $T$, over which the system delivers energy. This assumption neglects that failures could be precipitated by stress under highpower conditions. With these new definitions and assumptions, the duration curve is modified by PR and availability, as shown in Figure 2, and modeled in Equation 6. Note that this is a new 
way of thinking about PR and A: it is clear now that $\mathrm{PR}<1$ means a reduction in instantaneous power, so that it has a meaningful value over any time period; whereas $\mathrm{A}<1$ means a reduction in the number of hours over which energy is delivered in the time period. This replaces the notion that PR is reduced by both inefficiencies and down time. We strive in this paper to distinguish between these two performance parameters - both are currently misunderstood and applied in inconsistent ways; however, we assert that this treatment is driven by standardized [7] definitions of $\mathrm{PR}$ and $\mathrm{A}$, rather than contrary to them. Figure $2 \mathrm{a}$ shows the duration curve for $\mathrm{PR}=1$ and $\mathrm{PR}=0.8$; and Figure $2 \mathrm{~b}$ shows the duration curve for $\mathrm{A}=1$ and $\mathrm{A}=0.8$. 


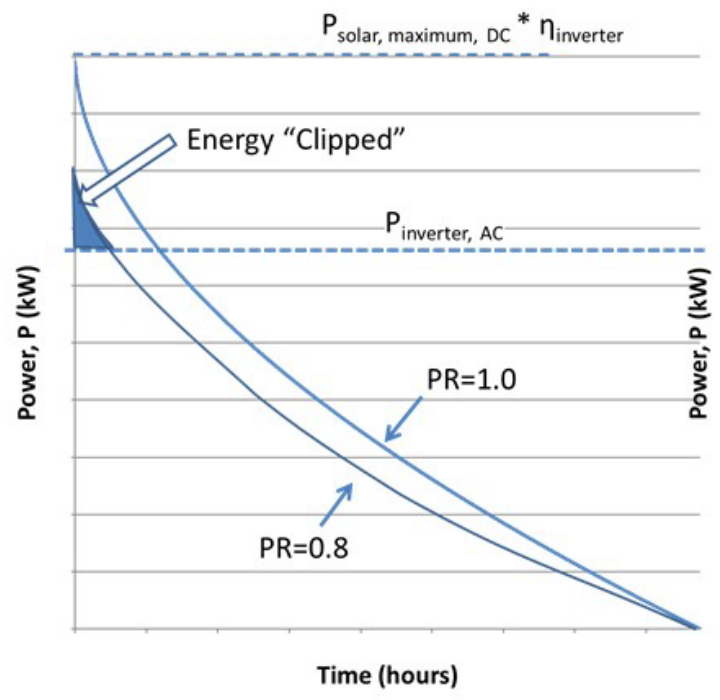

(a) Effect of Performance Ratio

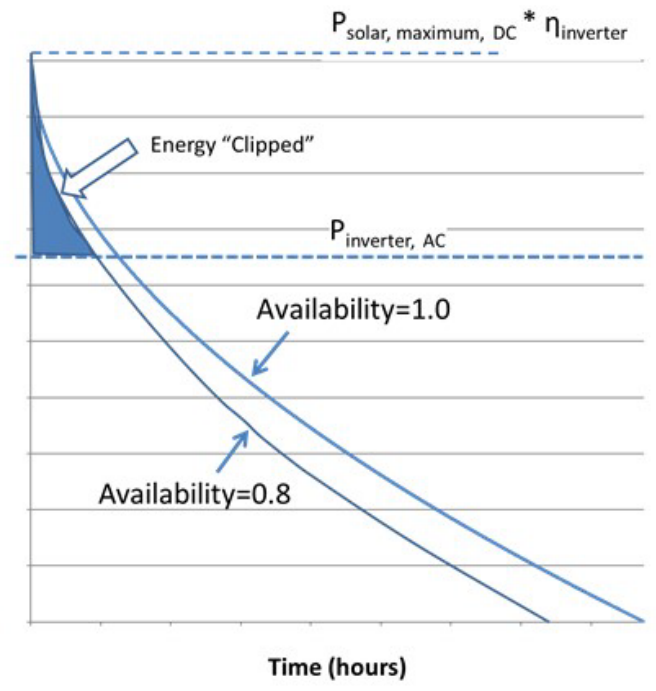

(b) Effect of Availability

Figure 2. The duration curve for PV power production is affected differently by a change in PR (a) than it is for availability (b), which has implications for amount of inverter clipping and optimal $A C / D C$ ratio. [figure by the author]

\subsection{Estimated Annual Energy Production and Power Duration Curve Modified by $\mathrm{PR}<1$ and $\mathrm{A}<1$}

The analysis period, $\mathrm{T}$, can be any duration of time, but an annual (1-year) period is conventional in solar analysis due to the seasonal cycle of the solar resource. So, the time period over which availability, A, determined here is 1 year. Annual energy production of the PV systems is based on the resource information as reported in the CF, as reduced by PR and availability. In estimating annual energy production, we invoke our definition that PR is instantaneous underperformance and our assumption that hours lost to availability are spread proportionally across all power levels in the distribution. Thus, PR and availability are independent of each other, and annual energy production may be written as:

Equation 5

$$
E_{\text {production }}=\left(P R * P_{\text {rated }}\right) *(A * T) * C F
$$

Where $\mathrm{P}_{\text {rated }}(\mathrm{kW}$ of PV generator), is the rated capacity defined in a way that is consistent with the definition of capacity factor, and $\mathrm{T}$ is the expected operational hours over which the capacity factor is defined, which might be 4,380 hours (365 days*12 hours/day). In other words, to calculate energy production, Equation 5 modifies power expected by PR and modifies the time over which power is delivered by A and multiplied by capacity factor that depends on location. Notice that annual energy production is a virtual potential to generate that amount of AC energy if not curtailed or clipped by inverter capacity (the clipped AC energy is never actually generated). 
The effect of $\mathrm{PR}<1$ is to reduce the power level $\mathrm{P}$; the power level is reduced by this factor in every hour. The effect of $A<1$ is to reduce the number of hours over which all power levels are generated, and the total number of hours $\mathrm{T}$ is also reduced by this factor. The duration curve for $\mathrm{P}$ thus modified for $\mathrm{PR}<1$ and $\mathrm{A}<1$ is given by the distribution:

Equation 6

$$
P=P R P_{\text {rated }}\left(1-(t /(A T))^{n}\right)
$$

DC power is the direct current from the PV array to the inverter; and AC power is the resulting alternating current from the inverter to the point of interconnection with the larger electrical system. The inverter capacity, $\mathrm{P}_{\text {inverter }}(\mathrm{kW})$ is the maximum AC power output of the inverter. $\mathrm{P}_{\text {inverter }}$ is taken to be constant over the analysis period $\mathrm{T}$, which is generally the case since capacity depends on the installed hardware; but this limits the accuracy of this method to applications with constant external curtailment constraints. An example of a constant constraint is PV systems in Germany required to install an inverter sized for no more than $0.7 \mathrm{AC} / \mathrm{DC}$ ratio, to increase hosting capacity for other PV systems on the network. An example of variable capacity inverter not appropriate for the method of this report would be if the utility were to actively curtail the output - because we assume here that the curtailment is the same across all power levels of the distribution and the utility is most likely to call for curtailment when power level is highest. At sunny times when the DC power $(\mathrm{kW})$ from the PV system exceeds the inverter capacity, then power clipped (not produced as AC power) is $E_{\text {clipped }}(\mathrm{kWh})$ and is determined by integrating the area under the distribution curve of Equation 6 but in excess of the load [Second Theorem of Calculus]. Similarly, the amount of energy delivered over the time period $\mathrm{T}$ as $\mathrm{AC}$ power is then calculated by integration-by-parts as the total production minus the clipped amount.

\subsection{Energy Clipped}

Energy clipped is energy that was not converted in the first place — but it is defined as the amount of AC energy that would have been delivered, but which was not delivered because AC power output was limited by a lower inverter capacity (see Figure 2). This is an issue related to system design rather than system operation, the size of the PV array and the inverter both being established in the design. So this analysis is not applicable to cases in which the inverter capacity is actively curtailed by a control signal. The integral of power $(\mathrm{kW})$ in excess of the inverter capacity $(\mathrm{kW})$ is evaluated as:

\section{Equation 7}

$$
E_{\text {clipped }}=\int_{0}^{t_{\text {clipped }}}\left(P-P_{\text {inverter }}\right) d t
$$

Substitution of the distribution of Equation 6 into Equation 7 gives:

Equation 8

$$
E_{\text {clipped }}=\int_{0}^{t_{\text {clipped }}}\left(P R P_{\text {rated }}\left(1-\left(\frac{t}{A T}\right)^{n}\right)-P_{\text {inverter }}\right) d t
$$


And multiplying through by $\mathrm{P}_{\text {rated }}$ gives:

Equation 9

$$
E_{\text {clipped }}=\int_{0}^{t_{\text {clipped }}}\left(P R P_{\text {rated }}-P R P_{\text {rated }}\left(\frac{t}{A T}\right)^{n}-P_{\text {inverter }}\right) d t
$$

The indefinite integral is evaluated by the second theorem of calculus:

Equation 10

$$
E_{\text {clipped }}=\left[P R P_{\text {rated }} t-\frac{P R P_{\text {rated }} t^{(n+1)}}{(n+1)(A T)^{n}}-P_{\text {inverter }} t+\text { constant }\right]_{0}^{t_{\text {clipped }}}
$$

And the definite integral is determined by evaluated the expression at both limits.

Equation 11

$$
E_{\text {clipped }}=P R P_{\text {rated }} t_{\text {clipped }}-\frac{P R P_{\text {rated }} t_{\text {clipped }}^{(n+1)}}{(n+1)(A T)^{n}}-P_{\text {inverter }} t_{\text {clipped }}
$$

The amount of time that the potential power from the PV array exceeds the inverter capacity is $t_{\text {clipped }}$ (hours). At the power level where inverter power is barely clipped:

Equation 12

$$
P_{\text {inverter }}=P=P R P_{\text {rated }}\left(1-\left(\frac{t_{\text {clipped }}}{A T}\right)^{n}\right)
$$

Rearranging terms gives:

Equation 13

$$
\left(\frac{t_{\text {clipped }}}{A T}\right)^{n}=1-\frac{P_{\text {inverter }}}{P R P_{\text {rated }}}
$$

Taking the natural logarithm of both sides gives:

Equation 14

$$
n \ln \left(\frac{t_{\text {clipped }}}{A T}\right)=\ln \left(1-\frac{P_{\text {inverter }}}{P R P_{\text {rated }}}\right)
$$

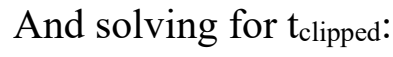

Equation 15 


$$
t_{\text {clipped }}=A T e^{\left[\frac{\ln \left(1-\frac{P_{\text {inverter }}}{P R P_{\text {rated }}}\right)}{n}\right]}
$$

Substitution of $t_{\text {clipped }}$ from Equation 13 into Equation 9 and combining terms yields:

Equation 16

$$
\begin{aligned}
E_{\text {clipped }}=( & \left.P R P_{\text {rated }}-P_{\text {inverter }}\right) A T e^{\left(\ln \left(1-\frac{P_{\text {inverter }}}{P R P_{\text {rated }}}\right) / n\right)} \\
& -\frac{P R P_{\text {rated }}}{(A T)^{n}(n+1)}\left(T e^{\left(\ln \left(1-\frac{P_{\text {inverter }}}{P R P_{\text {rated }}}\right) / n\right)}\right)^{(n+1)}
\end{aligned}
$$

Equation 16 describes $E_{\text {clipped }}$ as a function system design parameters ( $\mathrm{P}_{\text {rated }}$ and $\left.\mathrm{P}_{\text {inverter }}\right)$ and solar resource information ( $\mathrm{n}$ and $\mathrm{CF}$ ), and also incorporating operational parameters (values of $\mathrm{PR}<1$ and also for $\mathrm{A}<1)$.

\subsection{Energy Delivered}

Energy Delivered, $E_{\text {delivered, }}$ is the AC energy delivered to the offtaker of the power. It is evaluated by integration-by-parts as:

Equation 17

$$
E_{\text {delivered }}=E_{\text {Production }}-E_{\text {clipped }}
$$

Substitution of Equations 5 and 16 into 17 give:

Equation 18

$$
\begin{aligned}
& E_{\text {delivered }}=\mathrm{PRP}_{\text {rated }} * \mathrm{AT} * \mathrm{CF}-\left(P R P_{\text {rated }}-P_{\text {inverter }}\right) A T e^{\left(\ln \left(1-\frac{P_{\text {inverter }}}{P R P P_{\text {rated }}}\right) / n\right)} \\
& -\frac{P R P_{\text {rated }}}{(A T)^{n}(n+1)}\left(A T e^{\left(\ln \left(1-\frac{P_{\text {inverter }}}{P R P_{\text {rated }}}\right) / n\right)}\right)^{(n+1)}
\end{aligned}
$$

\subsection{LCC Calculation}

With Equation 18 for delivered energy, and with economic parameters representing initial cost, O\&M cost, and value of power produced, we can write the expression for LCC as a function of power capacity of the inverter, $\mathrm{P}_{\text {inverter, }}$ and the other parameters.

Equation 19 


$$
\begin{aligned}
& \text { LCC }=C_{\text {initial,fixed }}+c_{\text {initial }, D C} P_{\text {maximum }, D C}+c_{\text {initial }, A C} P_{\text {inverter }}+C_{O \& M, f i x e d} \\
& +c_{O \& M, D C} P_{\text {maximum }, D C} p w f+c_{O \& M, A C} P_{\text {inverter }} p w f \\
& -r_{\text {utilityrate }}\left[\operatorname{PR} P_{\text {rated }}\right. \text { A T CF } \\
& -\left(P R P_{\text {rated }}-P_{\text {inverter }}\right) A T e^{\left(\ln \llbracket \frac{1-\frac{P_{\text {inverter }}}{P R P_{\text {rated }}}}{n}\right)} \\
& \\
& \left.-\frac{P R P_{\text {rated }}}{(A T)^{n}(n+1)}\left(A T e^{\left(\ln \llbracket \frac{1-\frac{P_{\text {inverter }}}{P R P_{\text {rated }}}}{n}\right)}\right)^{(n+1)}\right] p w f
\end{aligned}
$$

$\mathrm{C}_{\text {initial,fixed }}$ is the cost of the PV system in addition to cost for the DC part of the system or the AC part of the system and is mostly soft costs (marketing, design, permitting, metering, and so on) independent of size.

$\mathrm{C}_{\text {initial, }} \mathrm{DC}$ is the per unit (per $\mathrm{kW}$ ) cost for the DC parts of the system, including PV modules, conductor, conduit, array rack, foundation, and their accessories and installation.

$\mathrm{C}_{\text {initial, }} \mathrm{AC}$ is the per unit (per $\mathrm{kW}$ ) cost for the $\mathrm{AC}$ parts of the system, including inverter, transformer, AC switchgear, and their accessories and installation.

Co\&M, fixed, CO\&M, DC and CO\&M, AC are the per kW O\&M costs of the fixed DC and AC parts of the system respectively.

$\mathrm{r}_{\text {electricity }}$ is the price saved or paid by others for delivery of electric energy from the PV system. All energy produced by the PV system is values at this rate, so the result would not be accurate if the actual savings or revenue are dominated by demand or time-of-use rates which vary.

PWF is the present worth factor, which is calculated according to analysis period (e.g., 25 years), discount rate (e.g. 3\%/year) and inflation rate (e.g. 2\%/year). The value of these economic parameters may be adjusted by incentives, taxes, and other factors.

The procedure to determine the power capacity of the inverter, $\mathrm{P}_{\text {inverter, }}$ that minimizes LCC, is to take the derivative of Equation 17 with respect to $\mathrm{P}_{\text {inverter; }}$ and then to solve for the value of $\mathrm{P}_{\text {inverter }}$ for which the derivative of LCC is zero.

\subsection{Example Application: Optimization of LCC Considering Effects of PR and Availability}

The objective is to determine the size (capacity, $\mathrm{kW}$ ) of an inverter, $\mathrm{P}_{\text {inverter }}(\mathrm{kW})$, based on minimizing LCC. The strategy is to take the derivative of LCC and set that equal to zero, and

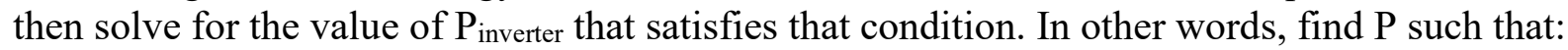


Equation 20

$$
\frac{d L C C}{d P_{\text {inverter }}}=0
$$

This analytical approach offers an advantage over numerical methods if there is need to perform very efficient sizing calculations driven by: (1) need to evaluate a very large number (tens of thousands) of project opportunity sites in an inventory of projects; (2) need for data transfer efficiency and computational efficiency in online and mobile apps; and (3) to increase the accuracy of screening studies, which are the earliest indicator of project opportunities. With this derivation, we can solve the problem with analytical methods (fundamental theorem of calculus), rather than numerical methods. This analytical method offers insight not visible in numerical methods.

The derivative of LCC as listed in Equation 18 would be:

Equation 21

$$
\frac{d L C C}{d P_{\text {inverter }}}=C_{\text {initial }, A C}+C_{O \& M, A C} p w f-r_{\text {electricity }} \frac{d E_{\text {delivered }}}{d P_{\text {inverter }}} p w f
$$

But $\mathrm{E}_{\text {delivered }}$ is also a function of $\mathrm{P}_{\text {inverter, }}$ so this will be hard to solve. Substituting in the expression for $E_{\text {delivered: }}$

Equation 22

$$
\begin{aligned}
\frac{d L C C}{d P_{\text {inverter }}}= & C_{\text {initial }, A C}+C_{O \& M, A C} p w f-r_{\text {electicity }}\left\{d / d P_{\text {inverter }}\left\{\mathrm{P}_{\text {rated }} * \mathrm{PR} * \mathrm{~A} * \mathrm{CF}\right.\right. \\
& * \mathrm{~T}-\left(P R P_{\text {rated }}-P_{\text {inverter }}\right) A T e^{\left(\ln \left(1-\frac{P_{\text {inverter }}}{P R P \text { rated }}\right) / n\right)} \\
& \left.-\frac{P R P_{\text {rated }}}{(A T)^{n}(n+1)}\left(\mathrm{AT} e^{\left(\text {ln(1- }\left(-\frac{P_{\text {inverter }}}{\text { PRP rated }}\right) / n\right)}\right)^{(n+1)}\right\} p w f
\end{aligned}
$$

Since Equation 22 is a long expression, it is helpful to break it into parts and identify the derivative of each of the terms individually. Because they are long, the equations are displayed in linear notation:

$$
\begin{aligned}
& \mathrm{d} / \mathrm{dP}_{\text {inverter }}\left\{-\left(\mathrm{PRP}_{\text {rated }}-\mathrm{P}_{\text {inverter }}\right) \mathrm{ATe}^{\wedge}\left(\left(\ln \left(1-\mathrm{P}_{\text {inverter }} / \mathrm{PRP}_{\text {rated }}\right) / \mathrm{n}\right)\right\}=((1+\mathrm{n}) \mathrm{AT}(1-\right. \\
& \left.\left.\mathrm{P}_{\text {inverter }} / \mathrm{PRP}_{\text {rated }}\right)^{\wedge}(1 / \mathrm{n})\right) / \mathrm{n} \\
& \mathrm{d} / \mathrm{dP}_{\text {inverter }}\left\{-\mathrm{PRP}_{\text {rated }} /\left((\mathrm{AT})^{\wedge} \mathrm{n}(\mathrm{n}+1)\right)\left(\mathrm{ATe}^{\wedge}\left(\ln \left(1-\mathrm{P}_{\text {inverter }} /\left(\mathrm{PRP}_{\text {rated }}\right) / \mathrm{n}\right)\right)^{\wedge}(\mathrm{n}+1)=\right.\right. \\
& \mathrm{PRP}_{\text {rated }} /(\mathrm{AT})^{\wedge} \mathrm{n} /(\mathrm{n}+1)\left\{\left((\mathrm{n}+1) \mathrm{AT}\left(1-\mathrm{P}_{\text {inverter }} /\left(\mathrm{PRP}_{\text {rated }}\right)\right)^{\wedge}(1 / \mathrm{n}-1)(\mathrm{AT}(1-\right.\right. \\
& \left.\left.\left.\mathrm{P}_{\text {inverter }} /\left(\mathrm{PRP} \mathrm{P}_{\text {rated }}\right)\right)^{\wedge}(1 / \mathrm{n})\right)^{\wedge} \mathrm{n}\right) /\left(\mathrm{n} \mathrm{PRP}_{\text {rated }}\right) \\
& \mathrm{d} /\left(\mathrm{dP}_{\text {inverter }}\right)\left(\left(\mathrm{PRP}_{\text {rated }}-\mathrm{P}_{\text {inverter }}\right) \mathrm{AT}^{\wedge}\left(\log \left(1-\mathrm{P}_{\text {inverter }} /\left(\mathrm{PR} \mathrm{P}_{\text {rated }}\right)\right) / \mathrm{n}\right)+\left(\mathrm{PRP}_{\text {rated }}(\mathrm{AT}\right.\right. \\
& \left.\left.\left.\mathrm{e}^{\wedge}\left(\log \left(1-\mathrm{P}_{\text {inverter }} / \mathrm{r}\right) / \mathrm{n}\right)\right)^{\wedge}(\mathrm{n}+1)\right) /\left((\mathrm{AT})^{\wedge} \mathrm{n}(\mathrm{n}+1)\right)\right)=\left(( \mathrm { AT } ) ^ { \wedge } ( 1 - \mathrm { n } ) \left(1-\mathrm{P}_{\text {inverter }} /(\mathrm{PR}\right.\right. \\
& \left.\left.\mathrm{P}_{\text {rated }}\right)\right)^{\wedge}(1 / \mathrm{n})\left((\mathrm{n}+1) \mathrm{P}_{\text {inverter }}(\mathrm{AT})^{\wedge} \mathrm{n}-\mathrm{PRP}_{\text {rated }}\left(\left(\mathrm{T}\left(1-\mathrm{P}_{\text {inverter }} /\left(\mathrm{PRP}_{\text {rated }}\right)\right)^{\wedge}(1 / \mathrm{n})\right)^{\wedge} \mathrm{n}+(\mathrm{n}+\right.\right. \\
& \left.\left.\left.1)(\mathrm{AT})^{\wedge} \mathrm{n}\right)\right)\right) /\left(\mathrm{n}\left(\mathrm{PRP} \mathrm{P}_{\text {rated }}-\mathrm{P}_{\text {inverter }}\right)\right)
\end{aligned}
$$




$$
\begin{aligned}
& \mathrm{d} /\left(\mathrm{dP} \mathrm{P}_{\text {inverter }}\right)\left(-\left(\mathrm{PRP}_{\text {rated }}-\mathrm{P}_{\text {inverter }}\right)(\mathrm{AT}) \mathrm{e}^{\wedge}\left(\log \left(1-\mathrm{P}_{\text {inverter }} /\left(\mathrm{PRP}_{\text {rated }}\right)\right) / \mathrm{n}\right)-\left(\mathrm{PRP}_{\text {rated }}(\mathrm{AT}\right.\right. \\
& \left.\left.\mathrm{e}^{\wedge}\left(\log \left(1-\mathrm{P}_{\text {inverter }} /\left(\mathrm{pr} \mathrm{P}_{\text {rated }}\right) / \mathrm{n}\right)\right)^{\wedge}(\mathrm{n}+1)\right) /\left((\mathrm{n}+1)(\mathrm{AT})^{\wedge} \mathrm{n}\right)\right)=\left((\mathrm{AT})^{\wedge}(1-\mathrm{n})(1-\right. \\
& \left.\mathrm{P}_{\text {inverter }} /\left(\mathrm{PRP}_{\text {rated }}\right)\right)^{\wedge}(1 / \mathrm{n})\left(\mathrm{PRP}_{\text {rated }}\left(\left(\mathrm{AT}\left(1-\mathrm{P}_{\text {inverter }} /\left(\mathrm{PRP}_{\text {rated }}\right)\right)^{\wedge}(1 / \mathrm{n})\right)^{\wedge} \mathrm{n}+(\mathrm{n}+1)(\mathrm{AT})^{\wedge} \mathrm{n}\right)-\right. \\
& \left.\left.(\mathrm{n}+1) \mathrm{P}_{\text {inverter }}(\mathrm{AT})^{\wedge} \mathrm{n}\right)\right) /\left(\mathrm{n}\left(\mathrm{PRP}_{\text {rated }}-\mathrm{P}_{\text {inverter }}\right)\right)
\end{aligned}
$$

Substitution of these derivatives into Equation 20 produces the equation for the derivative of LCC. This is the expression that will be set to zero to calculate the optimal value of $P_{\text {inverter }}$ that minimizes LCC.

Equation 23

$$
\begin{aligned}
\frac{d L C C}{d P_{\text {inverter }}}=0 & =C_{\text {initial }, A C}+C_{O \& M, A C} p w f-r_{\text {electricity }}\left\{\left((\mathrm{AT})^{\wedge}(1-n)(1\right.\right. \\
& \left.-P_{\text {inverter }} /\left(\mathrm{PR} P_{\text {rated }}\right)\right)^{\wedge}(1 / n)\left(P R P_{\text {rated }}((\mathrm{AT}(1\right. \\
& \left.\left.\left.-P_{\text {inverter }} /\left(\mathrm{PR} P_{\text {rated }}\right)\right)^{\wedge}(1 / n)\right)^{\wedge} n+(n+1)(\mathrm{AT})^{\wedge} n\right)-(n \\
& \left.\left.\left.+1) P_{\text {inverter }}(\mathrm{A} T)^{\wedge} n\right)\right) /\left(n\left(P R P_{\text {rated }}-P_{\text {inverter }}\right)\right)\right\}
\end{aligned}
$$

Equation 23 is a transcendental equation, which means that the variable $\mathrm{P}_{\text {inverter }}$ appears both in an exponential term and as a product multiplied by the exponential term. Many software products, such as the goal seek function in Microsoft Excel, can solve Equation 23 for $\mathrm{P}_{\text {inverter }}$ iteratively, and then $\mathrm{DC} / \mathrm{AC}$ ratio is calculated as $\mathrm{P}$ DC, maximum. $/ \mathrm{P}_{\text {inverter. }}$ 


\section{Results}

This derivation has resulted in an expression of LCC as a function of descriptors of the PV system cost and efficiency and the variability of the solar resource, and also as a function of important performance parameters PR and A. This results in a simple calculator that provides insight into the behavior of the LCC function and improves estimates of system cost effectiveness informed by imperfect $(<1)$ values of PR and availability.

\subsection{Range of Input Parameters}

Values for the input parameters of the optimization collected from the literature are listed in Table 2, and a representative of a $100 \mathrm{~kW}$ commercial-scale PV system in a distributed energy application.

Table 2. Selected values of Input Parameters to use in an example of the LCC and Optimization Calculations ( $\$ / \mathbf{k W}$ refers to $\mathbf{k W}$ of $\left.P_{\text {rated }}\right)$

\begin{tabular}{|c|c|c|c|}
\hline \multicolumn{4}{|l|}{ Input } \\
\hline Parameter & Units & $\begin{array}{l}\text { Reference } \\
\text { Value }\end{array}$ & Reference \\
\hline$P_{\text {maximum, }} \mathrm{DC}$ & $\mathrm{kW}$ & 100 & [no reference] \\
\hline$\eta_{\text {inverter,BOS }}$ & - & 0.89 & {$[21]$} \\
\hline C_(initial,fixed) & $\$$ & $\$ 43,000$ & {$[21]$} \\
\hline $\mathrm{C}_{-}$(initial,DC) & $\begin{array}{l}\$ / k W \\
\text { DC }\end{array}$ & $\$ 870$ & $([21]$ \\
\hline C_(initial,AC) & $\begin{array}{l}\$ / k W \\
A C\end{array}$ & $\$ 550$ & $([21]$ \\
\hline C_(O\&M,fixed) & \$/year & $\$ 420$ & PV O\&M Cost Model $[5,22]$ \\
\hline$C_{-}(\mathrm{O} \& M, D C)$ & $\begin{array}{l}\text { \$/kWD } \\
\text { C/year }\end{array}$ & $\$ 5.78$ & PV O\&M Cost Model, $[5,22]$ \\
\hline C_(O\&M,AC) & $\begin{array}{l}\text { \$/kWAC } \\
\text { lyear }\end{array}$ & $\$ 7.53$ & PV O\&M Cost Model, $[5,22]$ \\
\hline relectricity & $\$ / \mathrm{kWh}$ & $\$ 0.05$ & {$[1]$} \\
\hline Annual CF & - & 0.175 & Athens, Georgia; [23] \\
\hline PR & - & 0.917 & oSPARC statistics on 2,200 systems [3] \\
\hline A & - & 0.956 & (Huang et al.) [20] \\
\hline
\end{tabular}

\subsection{Example Optimization of AC/DC Ratio with PR<1 and A<1}

The following example shows the optimization calculation for a $100-\mathrm{kW}$ commercial system with input parameters that are the same as the reference values shown in Table 2. The PR is taken to be the average value of $P R=0.917$ and the availability is taken as $A=0.956$, which is the average value from both references in Table 1. In this example, with these inputs, the optimal

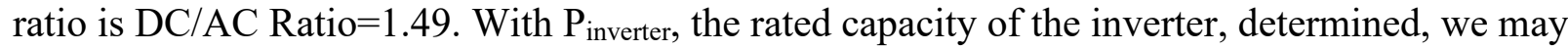
calculate the initial cost, operating cost, utility cost savings, LCC, and other details related to a project recommendation. 
Table 3. Example of Output Results for LCC and Optimization Calculations, including the effect of non-unity PR and Availability (using the input values from Table 2)

\begin{tabular}{|c|c|c|}
\hline \multicolumn{3}{|l|}{ Output } \\
\hline Parameter & Units & Value \\
\hline Optimal DC/AC Ratio & - & 1.49 \\
\hline LCC & $\$$ & $\$ 88,756$ \\
\hline Initial Cost (\$) & $\$$ & $\$ 167,020$ \\
\hline Life-Cycle O\&M Cost (\$) & $\$$ & $\$ 25,597$ \\
\hline $\begin{array}{l}\text { Life Cycle Cost of electricity } \\
\text { production (\$) }\end{array}$ & $\$$ & $\begin{array}{r}-\$ 107,189 \\
\text { (negative } \\
\text { cost } \\
\text { indicates a } \\
\text { savings or } \\
\text { revenue) }\end{array}$ \\
\hline $\begin{array}{l}\text { Life-Cycle Cost due to } \\
\text { Clipping }\end{array}$ & $\$$ & $\$ 3,327$ \\
\hline $\mathrm{d}($ LCC $) / \mathrm{dPinverter}$ & & $5.0941 \mathrm{E}-06$ \\
\hline
\end{tabular}




\section{Application to System Design: Inverter Sizing}

The implications of the optimal inverter sizing are further explored within this example of optimizing inverter size under varying values of PR and Availability.

\subsection{Validation of Optimization Equation $d(L L C)=0$}

To validate the optimal result, we now calculate LCC over a range of parameters and confirm that the value of $\mathrm{AC} / \mathrm{DC}$ Ratio reported based on $\mathrm{dLCC} / \mathrm{dP}=0$ is indeed the optimal value that minimizes LCC. LCC as calculated over values of DC/AC ratio from 1.2 to 2.0 is shown in Figure 3, and confirm the recommended size determined by taking $\mathrm{dLCC} / \mathrm{dP}$, setting the derivative equal to zero, and solving for the optimal value of $\mathrm{DC} / \mathrm{AC}$ ratio. For this validation, we use the representative input parameters from Table 2 . Figure 3 verifies that our $d(L C C)=0$ solution is coded properly, meaning consistent with our definitions and calculation of LCC. As seen in Figure 3, the differential method does indeed find the optimum, which in this case is a $\mathrm{DC} / \mathrm{AC}$ ratio $=1.49(\mathrm{AC} / \mathrm{DC}$ Ratio of 0.669$)$ and a resulting Life Cycle Cost of \$88,756. 


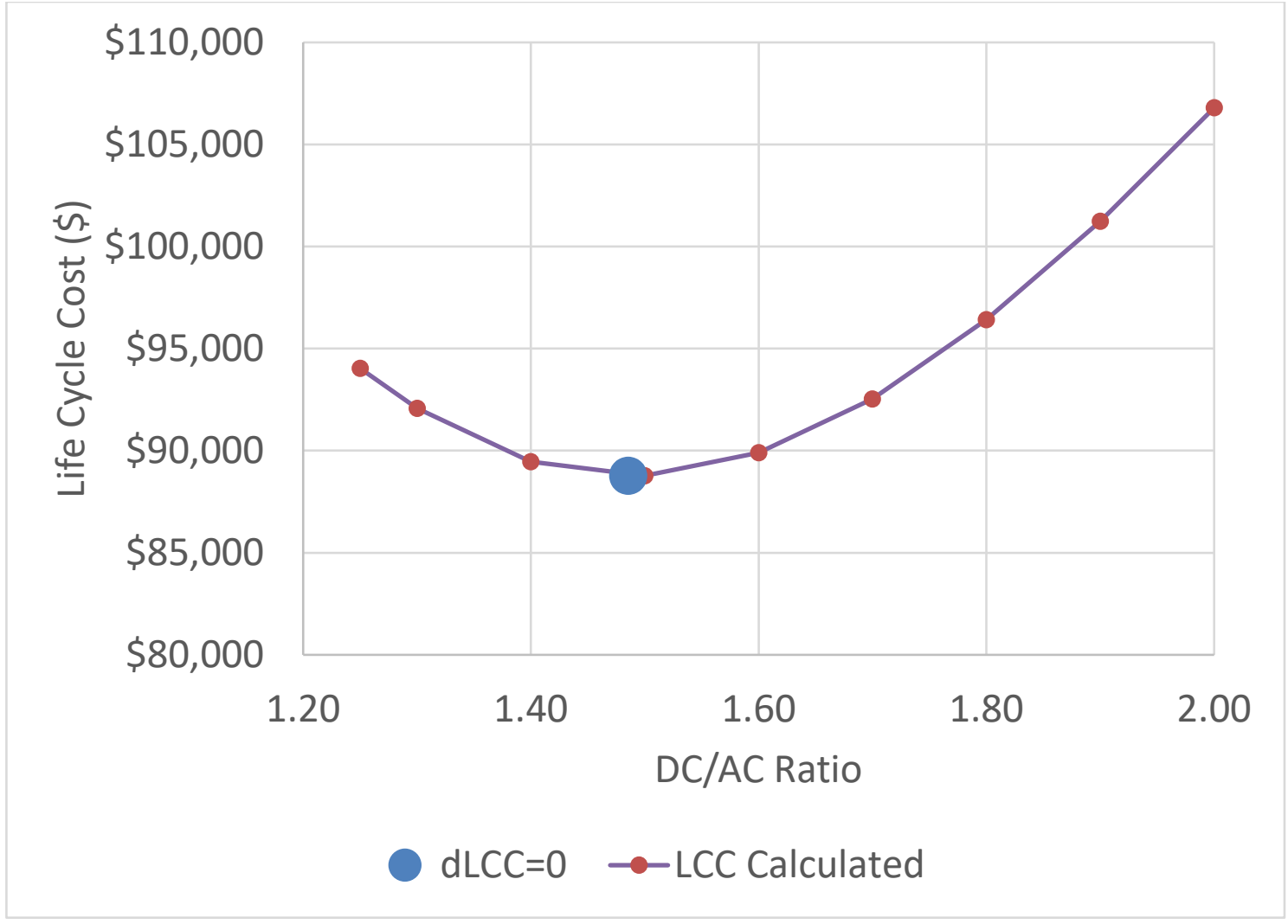

Figure 3. LCC calculated from Equation 19, compared to the optimal DC/AC ratio calculated using Equation 23 [figure by the author]

\subsection{How Optimal DC/AC Ratio Varies with PR (PR=0.7 to $P R=1.0$ )}

Having validated our optimization equation, we use it to calculate the optimal DC/AC ratio as a function of PR. Table 4 below lists the optimal DC/AC ratio for values of PR varying from 0.7 to 1.0, with all other variables at the reference values in Table 3 above, including availability, A, held at its reference value of $A=0.956$.

Table 4. Optimal AC/DC Ratio as a Function of Varying PR, with Other Values Held at the values listed in Table 3

\begin{tabular}{|l|r|r|r|r|}
\hline PR & 1 & 0.9 & 0.8 & 0.7 \\
\hline Optimal DC/AC Ratio & 1.36 & 1.51 & 1.70 & 1.95 \\
\hline
\end{tabular}

\subsection{How Optimal DC/AC Ratio Varies for Availability, $A=0.7$ to $A=1.0$}

Variations in Availability, A, also influence optimal DC/AC ratio. Here, optimal DC/AC ratio is calculated as a function of A. Table 5 below lists the optimal DC/AC ratio for values of Availability is varied from $A=0.7$ to $A=1 / 0$, with all other variables at the reference values in Table 3, including PR, held at its reference value of $\mathrm{PR}=0.917$. 
Table 5. Optimal DC/AC Ratio as a Function of Varying Availability, with Other Values Held from Table 2.

\begin{tabular}{|l|r|r|r|r|}
\hline Availability & 1 & 0.9 & 0.8 & 0.7 \\
\hline Optimal DC/AC Ratio & 1.48 & 1.50 & 1.52 & 1.54 \\
\hline
\end{tabular}




\section{Conclusion}

The effect of PR and availability on the LCC of a PV system has been analyzed, and the equation for LCC based on a new form of duration curve has been presented. The derivative of this LCC equation can be set to zero and solved for any of the independent variables, and here we solve for $\mathrm{d}(\mathrm{LCC}) / \mathrm{dP}_{\text {inverter }}$ to determine the optimal DC/AC ratio under different circumstances of $\mathrm{PR}$ and Availability.

The LCC and optimal DC/AC ratio depend on many different parameters related to initial cost and ongoing O\&M costs, as well as solar resource parameters and value of the electric power produced. So, there is no one single value for optimal DC/AC ratio-it depends on the parameters, such as AC and DC component costs, value of power generated, and, to the point of this paper, on PR and Availability as well. The equation presented here may be used to calculate an optimum under different situations; however, to illustrate the method and the importance of considering $\mathrm{PR}<1$ and $\mathrm{A}<1$ in the specification of systems, we survey the literature for reference values which are representative of current industry statistics, and we use the reference values in the calculation of optimal DC/AC Ratio and resulting LCC for varying PR and A values.

Results indicate that system design recommendations (optimal DC/AC ratio) are very sensitive to $\mathrm{PR}$, with the optimal ratio going up as the PR goes down. Optimal DC/AC ratio also depends on A, but the dependence is less sensitive, with optimal AC/DC ratio going up only slightly with decreasing A. This result lends some insight into the different impacts of PR and A, which may previously have been considered interchangeable. With $\mathrm{PR}=1$ and $\mathrm{A}=1$, the optimal $\mathrm{DC} / \mathrm{AC}$ Ratio is 1.36; but with the reference values of $P R=0.917$ and $A=0.956$, the optimal DC/AC Ratio is calculated at 1.49 , a significant difference in recommended inverter sizing.

The main value of this report is to provide insight into how the effects of PR and A are separable and to detail the effects on energy delivery and LCC. A practical application of the method is presented with the example of optimizing $\mathrm{DC} / \mathrm{AC}$ ratio for different values of $\mathrm{PR}$ and $\mathrm{A}$. 


\section{References}

[1] Bolinger M, Seel J. Utility-scale solar: empirical trends in project technology, cost, performance, and PPA pricing in the United States - 2018 Edition [Internet]. Berkeley, California: Lawrence Berkeley National Laboratory; 2018 Sep [cited 2018 Sep 29], p. 62. Available from: https://emp.lbl.gov/utility-scale-solar

[2] Best practices for operation and maintenance of photovoltaic and energy storage systems; 3rd Edition. Renew Energy. 2018; 153.

[3] About oSPARC - SunSpec Alliance - [Internet]. SunSpec Alliance. [cited 2019 Jun 19]. Available from: https://sunspec.org/osparchelp/

[4] Klise GT, Lavrova O, Gooding R. PV system component fault and failure compilation and analysis [Internet]. Albuquerque, New Mexico \& Livermore, California: Sandia National Laboratories; 2018 Feb, p. 38. Report No.: SAND2018-1743. Available from: https://classic.ntis.gov/help/order-methods/

[5] SunSpec PV OM cost model user guide - Beta.pdf [Internet]. Alliance for Sustainable Energy, LLC; 2017. Available from: https://sunspec.org/wpcontent/uploads/2016/03/SunSpecPVOMCostModelUserManual-Beta.pdf

[6] Dierauf T, Growitz A, Corporation S. Weather-corrected performance ratio. Renew Energy $2013 ; 22$.

[7] IEC TS 63019:2019 | IEC Webstore [Internet]. [cited 2019 Jun 18]. Available from: https://webstore.iec.ch/publication/27253

[8] Kumar NM, Dasari S, Reddy JB. Availability factor of a PV power plant: evaluation based on generation and inverter running periods. 2018. pp. 71-7. Available from:

https://www.scopus.com/inward/record.uri?eid=2-s2.0-

$85054059966 \&$ doi $=10.1016 \% 2$ fj.egypro.2018.07.035\&partnerID=40\&md5=f1879e491861ba33 a8bf00670a673aa2

[9] Demoulias C. A new simple analytical method for calculating the optimum inverter size in grid-connected PV plants. Electr Power Syst Res 2010; 80(10):1197-204.

[10] Faranda RS, Hafezi H, Leva S, Mussetta M, Ogliari E. The optimum PV plant for a given solar DC/AC converter. Energ 2015; 8(6):4853-70.

[11] Walker A. Software record number 13-04 dLCC Optimization.pdf. 2012, Available from https://www.labpartnering.org/p/labs/nrel\#experts or from the corresponding author.

[12] Wang HX, Muñoz-García MA, Moreda GP, Alonso-García MC. Optimum inverter sizing of grid-connected photovoltaic systems based on energetic and economic considerations. Renew Energy 2018; 118:709-17. 
[13] Camps X, Velasco G, de la Hoz J, Martín H. Contribution to the PV-to-inverter sizing ratio determination using a custom flexible experimental setup. Appl Energy 2015; 149:35-45.

[14] Chen S, Li P, Brady D, Lehman B. Determining the optimum grid-connected photovoltaic inverter size. Sol Energy 2013; 87(1):96-116.

[15] Khatib T, Ibrahim IA, Mohamed A. A review on sizing methodologies of photovoltaic array and storage battery in a standalone photovoltaic system. Energy Convers Manag 2016; 120:43048.

[16] Lin C-H, Hsieh W-L, Chen C-S, Hsu C-T, Ku T-T. Optimization of photovoltaic penetration in distribution systems considering annual duration curve of solar irradiation. IEEE Transact on Power Syst 2012; 27(2):1090-7.

[17] Solar radiation databases [Internet]. [cited 2019 Jun 19]. Available from: https://photovoltaic-software.com/principle-ressources/solar-radiation-databases

[18] IEC 61724-1:2017 | IEC Webstore | rural electrification, solar power, solar panel, photovoltaic, PV, smart city, LVDC [Internet]. [cited 2019 Jun 18]. Available from: https://webstore.iec.ch/publication/33622

[19] Jordan DC, Kurtz SR, VanSant K, Newmiller J. Compendium of photovoltaic degradation rates. Prog in Photovolt: Res and Appl 2016; 24(7):978-89.

[20] Huang HS, Jao JC, Yen KL, Tsai CT. Performance and availability analyses of PV generation systems in Taiwan. World Academy of Science, Engineering and Technology 2011; 78:309-13.

[21] Fu R, Feldman D, Margolis R, Woodhouse M, Ardani K. U.S. solar photovoltaic system cost benchmark: Q1 2017 [Internet]. Golden, Colorado: National Renewable Energy Lab; 2017 Sep, p. 73. Report No.: 68925. Available from: https://www.nrel.gov/docs/fy17osti/68925.pdf

[22] Walker A. PV O\&M cost model and cost reduction. PowerPoint presented at: 2017 Photovoltaic Module Reliability Workshop; 2017 Feb 28; Lakewood, Colorado.

[23] NSRDB Viewer | National Solar Radiation Database (NSRDB) [Internet]. [cited 2019 Jun 24]. Available from: https://nsrdb.nrel.gov/nsrdb-viewer 